\title{
Constructing the Facets of Altruistic Behaviors (FAB) Scale
}

\author{
Sabine Windmann@, Lucie Binder, and Martin Schultze \\ Department of Psychology, Goethe University Frankfurt, Germany
}

\begin{abstract}
Behavior is effectively altruistic to the degree that it is costly for the actor while benefiting others. In a series of preregistered studies, we constructed a 15-item self-report scale assessing three different facets of altruistic behavioral traits: help-giving, moral courage, and peer punishment. Item selection was performed with the help of Ant Colony Optimization (ACO) procedures as implemented in the stuart package for R. Confirmatory factor analysis of the three-factor measurement model showed excellent fit, outperforming classical item selection procedures. The scale was structure-validated in a second sample using a multiple group model that showed full measurement and structural invariance. A pilot study shows correlations of the subscales with economic game decisions. We discuss the scale structure and potential applications.
\end{abstract}

Keywords: altruism, costly punishment, moral courage, ant colony, scale construction

\section{The Concept of Altruism}

From an effective point of view, as is characteristic for biology, economics, and behaviorism, altruism can be defined as costly behavior that benefits others (Fehr \& Fischbacher, 2003; Kerr et al., 2004; Wilson, 1992). The definition relates to the input-output (cost-benefit) relation of actions without referring to mental states and allows altruism to be inferred from observed behaviors. Scientists choose such objective definitions in search of ultimate explanations when analyzing the effects of behavioral phenotypes on system interactions and population dynamics. Under this premise, only the consequences of actions count. By contrast, proximate variables, in describing the mediating mechanisms within the individual, refer to subjective intentions and goal states. What defines altruism from this viewpoint are the other-concerned benevolent intentions of the actor (Andreoni et al., 2010; Rodrigues \& Hewig, 2020). From an overall scientific standpoint, the issue cannot be which definition is "better," but what question is being pursued and for what purpose (Mayr, 1961; Tinbergen, 1963; Wilson, 1992, 2015).

Cost-benefit ratios preferred for oneself versus another also define Social Value Orientation (SVO; e.g., Murphy \& Ackermann, 2014). The framework describes altruism as a choice behavior that maximizes the benefit to the other while disregarding the outcome to oneself. The altruistic preference adjoins, but is distinct from, prosocial choice which maximizes joint gain for self and others or minimizes inequality between self and other. A similar distinction has been made in the biological altruism literature between absolute and relative fitness costs (Wilson, 2015) and in economics between strong and weak reciprocity (Fehr \& Fischbacher, 2003). Likewise, psychologists have referred to altruistic motivation only when the goal is purely and exclusively to promote the well-being of needy or suffering others (Batson et al., 2008), and rather speak of prosociality when indirect benefits of the act to the self may arise later from interactive system dynamics (e.g., Grant \& Berg, 2012, for organizational settings). Evolutionary theories see longterm effects of altruism as key to group selection (Wilson, 2015) and gene-culture coevolution (Gintis, 2011). From these perspectives, what counts as "benefit to all" is not a feature of the immediate act but depends on the temporal and contextual focus of the observer.

In fact, it is not hard to see in present times how the distribution of altruistic traits among human beings may influence evolutionary dynamics. Some of the most pressing global problems, including mass migration, worldwide epidemics, and climate change (Böhm et al., 2018; Luo et al., 2021; Van Lange et al., 2018), impose costs on societies, communities, and individuals to save and protect unknown strangers, distant populations, and future generations. To meet these challenges, "prosociality" may not be selfless enough, and "good" intentions may not suffice unless they result inconsequential actions. The crucial question in these contexts is rather whether and to what degree members of a group or society are prepared to perform costly acts that benefit others more than themselves. To advance and aid the relevant research, the present study is devoted to efficiently constructing a measurement tool that can measure behaviorally defined altruistic traits. 


\section{The Facets of Altruistic Behaviors}

The research on altruism is multidisciplinary and diverse, and various facets of altruistic behaviors have been described. In the psychological literature, altruistic behavior has most often been equated with help-giving (Batson, 2010; Batson et al., 1981; Cialdini et al., 1997; Rushton et al., 1981), also termed altruistic rewarding in other domains (Fehr \& Fischbacher, 2003). This means sharing one's resources with needy or deserving others, be it time, money, goods, energy, information, cognitive resources, or even blood and internal organs. In extreme cases, the behavior may imply risking one's life to save that of another (Rand \& Epstein, 2014).

In recent years, however, two other facets of altruism have emerged in the literature that appear systematically distinct from the kind of caring and other-befriending behaviors that exemplify helping and sharing. Specifically, these are socially antagonistic and confrontational types whose main characteristics are to oppose fairness violations and moral transgressions (Fehr \& Gächter, 2002; Halmburger et al., 2017; Pfattheicher \& Keller, 2017). Though less agreeable than helping, the two behavioral types are nonetheless altruistic in that they are costly and risky for the actor/s while establishing or defending norms and virtues of the community or society, hence providing a benefit for all. It is essential to consider such remedial forces in assessing altruism because these reduce and prevent the exploitation, withdrawal, and ultimately extinction of help-giving traits within groups (e.g., Fehr \& Gächter, 2002; Wilson, 2015).

Two research strains have developed with only very little crosstalk between them. The first is concerned with moral courage. This represents the willingness to defend ethical values against social threats, typically against a social power gradient, thereby putting one's own social status and personal well-being at risk (Bronstein et al., 2007; Halmburger et al., 2015; Jonas \& Brandstatter, 2004; Niesta Kayser et al., 2010). Like helping, moral courage is selfless, but unlike helping, it opposes wrongdoing instead of compensating or strengthening specific individuals. Notably, the two behaviors are conflated when one of the most efficient ways by which a victimized individual can be helped is by confronting their perpetrator/s, a situation that is described in many items of the Munich Civil Courage Instrument (Kastenmüller et al., 2007); for instance, when a parent hits their 3-year-old child. In fact, this type of conflation is inherent to all kinds of bystander interventions, situations in which the independent observer of a crime or misconduct helps the affected victim/s through interference (Baumert et al., 2013a; Darley \& Latané, 1968; Fischer et al., 2011). To decontaminate the term moral courage, we propose not to reserve it for reactions against observed offenses targeted at a specific (group of) individual/s.
Instead, we would relate it more generally to the pursuit of one's moral values (civil democratic values in the case of civil courage), both reactively and proactively, through opposition against powerful social forces (Halmburger et al., 2015; Landmann \& Hess, 2017).

The second form of confrontational altruism, termed costly peer punishment, has emerged from economic game settings. Players are allowed to pay for the punishment of unfair other players who have refused to contribute their fair share to an investment game but accept equal payoffs. Experimental studies have established that costly punishment effectively increases group cooperation by deterring such free riding so that all players collectively benefit from the punishment while the punisher themselves carries the net costs (Fehr \& Fischbacher, 2004; Fehr \& Gächter, 2002). The phenomenon is termed second party punishment when it occurs between interacting peers and third party punishment when the punisher is merely a bystander who has passively observed the unfair play (Fehr \& Fischbacher, 2004). Both these forms appear to show little or no correlation with voluntary sharing (helping) as assessed by the Dictator Game (Supplementary Tables 1-3 in Peysakhovich et al., 2014, but note that Pearson correlations were used even though data distributions from the Dictator Game are usually not unimodal and symmetric [Engel, 2011], leading to potential bias in these estimates [Bishara \& Hittner, 2015]).

One drawback of peer punishment emerges when the punishment is not efficient enough, meaning it is too costly relative to the group benefit, and thus reduces the overall payoff of the group (Dreber et al., 2008; Fehr \& Rockenbach, 2003). Additionally, the punishment entails the risk of retaliation, which can spiral into destructive feuds and vendettas in repeated interactions (Fehl et al., 2012; Nikiforakis \& Engelmann, 2011). For those reasons, players may be reluctant to choose the punishment option, letting others perform the punishment and giving rise to a "second-order" free-riding problem (Boyd et al., 2003; Perc, 2012). In view of these problems, some scholars have questioned whether costly punishment among peers exists in the real world, outside the imperative lab setting (Guala, 2010). Many, however, believe in coordinated forms, where punishment power is shared or centralized (Boyd et al., 2010; Gross et al., 2016; Molleman et al., 2019; Wu et al., 2016). For the coordination process, gossip is thought to play an important role (Feinberg et al., 2014; Wu et al., 2016). Overall, it seems reasonable to conclude that individuals can engage informally in peer punishment by coordinating group activities against unfair group members. Netto costs would be highest for the initiating individual, yet their act would serve the welfare of the group by effectively deterring free-riding, thereby increasing and stabilizing cooperation levels. 
According to our knowledge, no prior study has systematically addressed the question of whether costly peer punishment can be distinguished, conceptually and empirically, from moral courage (but see Kinnunen et al., 2015; Kinnunen \& Windmann, 2013). Both are confrontational, antagonistic behaviors that satisfy the behavioral definition of (at least weak) altruism. One crucial difference between the two, however, is that peer punishment serves to defend established norms, in accord with the values of the reference group, whereas moral courage, as defined here, may undermine or even challenge such norms by questioning the "rules of the game", as it were, thereby offering the innovative and transformative potential for the system as a whole. Second, with its rooting in experimental game settings and the expected peer group's backup, peer punishment entails rather circumscribed risks, at least under anonymous and one-shot conditions, whereas moral courage bears unpredictable and potentially immense threats. At the extreme, the consequences can even be fatal, as in the historical cases of Martin Luther King or Mahatma Gandhi, individuals who were by no means concerned with punishing peers but proactively pursued a moral mission. Acts of moral courage are frank, visible, direct, and personal, whereas peer punishment can be hidden, indirect, and secret while satisfying our definition of (weak) altruism for as long as it incurs net costs for the actor. A third difference is that peer punishment, by definition, describes interactions among peers who are at the same level of the social hierarchy, whereas moral courage operates against a power gradient by challenging authorities or majorities who have the means to respond with directed retaliation and repercussion. An ultimate example is the prominent and exceptional case of Edward Snowden, who opposed practices of the highest levels of governmental administration, leading to his relentless persecution and factual ostracism. Whistleblowing in opposition against authorities, supervisors, or the majority's interests is prototypical for morally courageous acts, if done personally (Dungan et al., 2019; Waytz et al., 2013).

To summarize, the literature has characterized three facets of altruism which we think may be conceptualized as distinct factors at the behavioral level: Help-giving (HG), moral courage (MC), and peer punishment (PP). The goal of the studies reported in this article is to construct a self-report questionnaire that can be used to reliably measure these three traits with high efficiency.

\section{Item Construction and Item Selection Using Ant Colony Optimization Procedures}

We designed a German self-report questionnaire aimed at assessing the three facets of altruistic behavioral (FAB) traits: help-giving (HG), moral courage (MC), and costly peer punishment $(\mathrm{PP})$. We proceeded as preregistered at https://osf.io/2buh6.

The items of the scale were constructed as follows. First, each item was formulated to represent one of the three altruistic facets (see Electronic Supplementary Materials, ESM 1, Section 1.1), with larger conceptual variation between the components than within. Second, all items referred to actual behaviors (as opposed to values and attitudes) as much as possible, thereby reducing social desirability biases and maximizing predictive validity. Some items asked in subjunctive for the willingness to perform a behavior (i.e., risking one's life to save someone else's) because the described action is highly indicative, albeit rare. Third, not all items contained all elements of the complex behavioral facets to the same degree. Their focus varied somewhat to allow for natural variation and non-suggestive phrasing.

In total, 57 items were constructed (listed in ESM 1, Table E1, Section 1.2). Subsequently, the process of item selection for the three subscales was performed, first, via classical procedures, and second, using the stuart approach (Schultze, 2017; Schultze \& Eid, 2018), which treats the item selection procedure as a combinatorial problem (specifically, as an I-dimensional multiple knapsack problem with assignment restrictions). Ant Colony Optimization (ACO) was used as described by Schultze (2017). Its approximative approach allows achieving almost optimal solutions at relatively low computational costs (Dorigo \& Stützle, 2010).

Details of the procedure are as follows: Item selection is performed iteratively. Initially, sets of items are drawn randomly from the item pool to form multiple possible solutions. Using confirmatory factor analysis (CFA), the psychometric quality of each of these solutions is evaluated with regards to a number of predefined criteria (e.g., model fit, reliability, and latent correlative structure). All items used in a solution are then rewarded for their participation in good solutions by depositing the quality of these solutions on the so-called pheromone. This pheromone is used to weigh the probability of an item being selected in the next iteration, where it is again updated in line with the quality of solutions this item was a part of. As the number of iterations increases, the pattern becomes clearer, leading to an efficient (but not necessarily optimal) solution (Schroeders et al., 2016).

The advantage of ACO is that it allows researchers to define the desired characteristics of their scale in terms of factorial structure, goodness-of-fit, and numbers of items. For short-scale development, this has been shown to outperform classical approaches (Janssen et al., 2017; Leite et al., 2008) due to its computational efficiency and ability to optimize multiple criteria simultaneously 
(Olaru et al., 2018). Additionally, it provides an automated and reproducible procedure that is much less reliant on individual decisions than the manual selection of items.

After primary scale construction, we validated the selection in a second sample (Study 2). Finally, we add information from a pilot study on the criterion validity of the final scale (Study 3).

All data and scripts are available at https://osf.io/jvp84/? view_only = ef93c7f4497b487483abae2fbb998e25.

\section{Study 1}

We presented the full item pool to participants and then performed item selection via classical analyses and ACO procedures. We also presented seven items about civil courage (CC) to ensure (in our Western culture sample) that MC items are being interpreted as a defense of ethical (not egoistic) values, presuming that most of our participants would hold civil-democratic values. In sum, 64 items were presented.

\section{Methods}

\section{Participants}

The sample consisted of 381 German-speaking participants, mean age 43.0 years $(S D=13.2$; range: $18-70), 52 \%$ female. In total, 413 participants had been recruited through a commercial panelist and received approximately $€ 2.50$ for online participation. The sample was quoted in terms of age, gender, and education. In line with the preregistration, we excluded participants who completed the survey in less than $5 \mathrm{~min}$ (32 participants). No participants had to be excluded for low survey motivation or poor understanding of the items as assessed by the five motivational statements in the survey.

\section{Materials}

All 64 items on altruistic behavioral traits and CC were rated on a 6-point scale labelled $1=$ strongly disagree, $2=$ disagree, $3=$ rather disagree, $4=$ rather agree, $5=$ agree, and $6=$ strongly agree. To ensure participants' engagement, two control questions were included asking the participant to check a predefined answer option. Incorrect response led to immediate abort.

Regarding CC, seven items were constructed that describe behaviors by which civil democratic values (human rights according to the UN charta) are vigorously defended. Only the five best items based on item-scale correlations and factor loadings were used (see ESM 1, Section 1.4 and note that bruteforce from the stuart package selected the same five items). McDonald's $\omega$ for the five CC items was .84.
The short German Kurzskala für soziale ErwünschtheitGamma (KSE-G; Kemper et al., 2012) was used with a 6-point response scale. It measures social desirability as the tendency to give a positive description of oneself and understate negative qualities by six items in total.

A set of five motivational statements dealt with how difficult it was to answer the questions and how much effort the participants had put into answering them. With one item each, living conditions in terms of financial resources, free time and social responsibilities (e.g., custody for a child) as well as voting preferences were taken for exploratory reasons (not considered further).

\section{Procedure}

The online survey (implemented in Unipark EFS Survey, Version 18.4, 2018, Questback $\mathrm{GmbH}$ ) started with the items presented in randomized order, intermixed with items of the KSE-G and the two control questions. Thereafter, participants were asked to rate their survey motivation and living conditions and indicate demographic information (ESM 1, section 1.5). On average, answering the entire survey took $13 \mathrm{~min}$.

\section{Statistical Analyses}

Item selection was performed with the Max-Min-AntSystem (MMAS algorithm; Stützle, 1998) implemented in the stuart package (Version 0.7.3; Schultze, 2018) for $\mathrm{R}$ (Version 3.6.0; R Core Team, 2019). For the CFA, we defined a three-factorial model with no cross-loadings and five items for each factor.

We included model fit as well as a reliability criterion in the objective function that determines the quality of a solution. Regarding model fit, we took both the incremental fit index CFI (comparative fit index; Bentler, 1990) and the absolute fit index RMSEA (root mean square error of approximation; Steiger \& Lind, 1980). We used logistic functions of CFI and RMSEA in line with the recommendations made by Schultze and Eid (2018) to ensure theoretical bounds on the objective functions as well as to allow for an increased degree of discrimination between solutions close to traditional cut-off values for these fit criteria.

$$
\begin{aligned}
\varphi_{\mathrm{CFI}} & =\frac{1}{1+e^{-100 \times(\mathrm{CFI}-.95)},} \\
\varphi_{\mathrm{RMSEA}} & =\frac{1}{1+e^{-100 \times(\mathrm{RMSEA}-.06)}} .
\end{aligned}
$$

Additionally, we included a structural equation modeling (SEM)-specific measure of reliability as Yang and Green (2010) proposed to ensure that the scale measures the constructs as reliably as possible. In this case, the reliability measure is identical to McDonald's $\omega$ (McDonald, 1999). We used the lowest of the three facet-specific reliabilities in the objective function in the following fashion: 


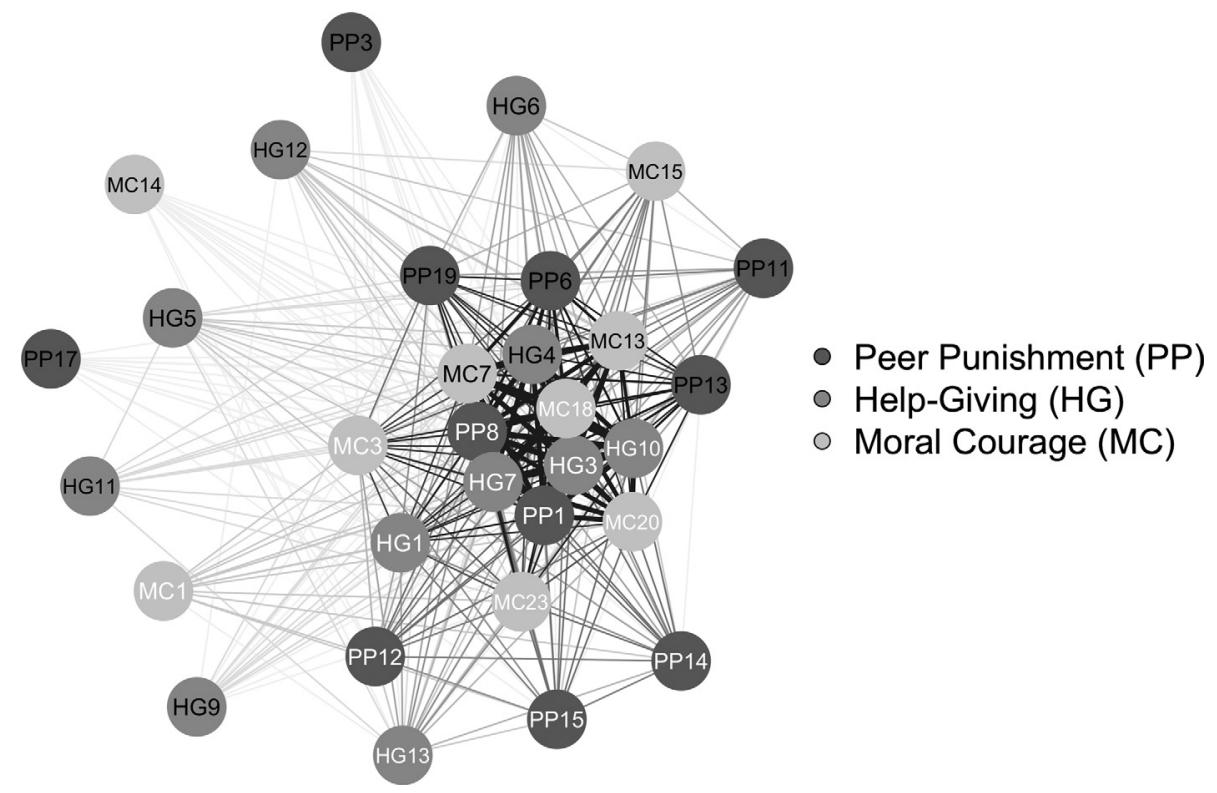

Figure 1. Network structure of the selection frequencies across the 25 runs of the item selection procedure. Each node represents one item, and items that were not selected in at least one run are omitted. Node labels are white for the items that were selected in the best solution overall. Edge strength indicates the relative frequency by which the two connected items were selected together. All items were positively framed except HG12 and HG6 (which were inverted).

$$
\varphi_{\mathrm{Rel}}=\frac{1}{1+e^{-100 \times(\min (\operatorname{Rel})-.7)}}
$$

In order to consider model fit and reliability equally when determining the quality of a solution, pheromone contributions were combined to the following optimization function with theoretical limits from 0.001 to 1.955 :

$$
\varphi_{\text {overall }}=\frac{\varphi_{\mathrm{CFI}}+\varphi_{\mathrm{RMSEA}}}{2} \varphi_{\mathrm{Rel}} .
$$

All parameters required for the MMAS algorithm were set according to the recommendations of Schultze (2017). The measurement models generated by the algorithm were estimated using lavaan (Version 0.6-3; Rosseel, 2012) with their parameters being estimated using maximum likelihood estimation with Satorra-Bentler-corrected test statistic (MLM) in order to deal with violations of normality.

\section{Results}

Primary analyses without the ACO procedure are reported briefly here as preregistered at https://osf.io/2buh6 (note that we changed the label "AP" [for "Altruistic Punishment"] in the preregistration to "PP" [for "Peer Punishment"] in this article as PP refers more specifically to group-related activities, whether or not these are altruistically motivated).

(1) "Classical test-theoretical item analysis based on item characteristics (proportions)" in combination with 5 . exploratory factor analysis with direct oblimin rotation" (see ESM 1, Section 1.2). In brief, this analysis suggested a 3 -factorial solution interpreted as MC,
PP, and HG, with goodness-of-fit indices of $\chi^{2}(627)=$ $1,410.25, p<.001, \mathrm{RMSEA}=.057, \mathrm{SRMR}=.047, \mathrm{CFI}$ $=.840$; the last one not fulfilling the criterion set for acceptable model fit in the preregistration. Misfit was mainly due to residual correlations between items of the same factor, which were not accounted for by the three-factorial solution. This suggests more overlap between specific items than could be captured by this model, indicating a necessity to select items that adhere to the strictly three-dimensional structure without additional similarities of items distorting the content structure of the final scale.

(2) "Exploratory Structural Equation Modeling (ESEM) with two anchor items per subscale" selected by three experts showed a three-factorial solution (see ESM 1, Section 1.3) with RMSEA $=.048, \mathrm{SRMR}=.057$, CFI $=.753$ (unacceptable), which involved a number of items with cross-loadings.

(3) Comparison of "the original three factor solution to a revised two-factor solution in which no AP items are predefined, and all AP items are allowed to load freely on the two other factors" (see ESM 1, Section 1.3) showed no support for the assumption of Peer Punishment collapsing into two subfactors while the threefactorial model showed acceptable fit in terms of RMSEA (.048) and SRMR (.054), though not in terms of CFI (.760). The analysis had been done to see whether the three-factorial model could be replaced by a two-factorial model in which PP items describing "protecting the group" load on the help-giving factor, and PP items "retaliating against fairness norm violations" load on the moral courage factor; the answer to which was negative. 


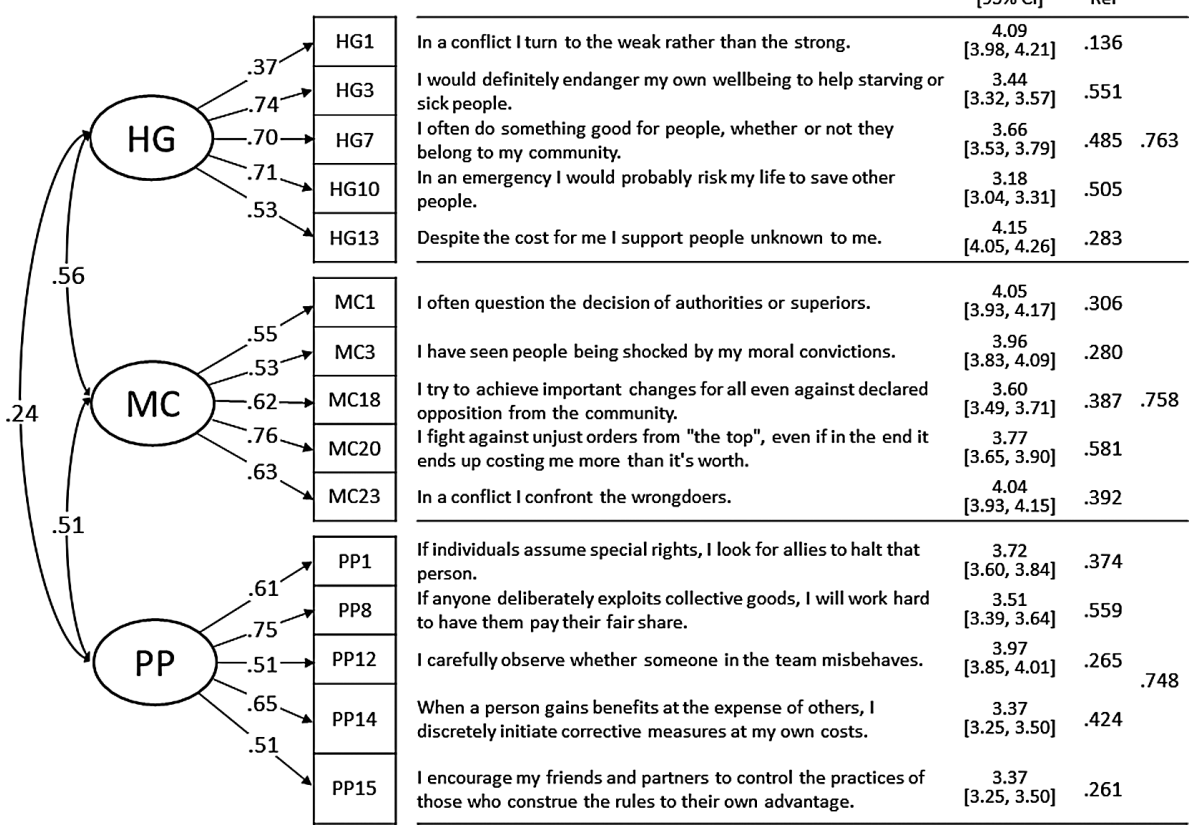

Figure 2. Path diagram of the measurement model of the final solution in Study 1 involving the three factors Help-Giving (HG), Moral Courage (MC), and Altruistic Peer Punishment (PP). Standardized parameter estimates are shown. No inverted items were contained in the final solution. For original item wordings in German (see Appendix).

Since neither solution was found satisfactory, we proceeded with the secondary analysis (5.), performing item selection with the ACO as implemented in the stuart package for $\mathrm{R}$.

\section{Performance of the ACO Selection Procedure}

In total, 262,448 models were calculated in 25 runs of the algorithm. Of these, a total of 201,742 solutions were unique, meaning that approximately $0.00002 \%$ of all possible combinations were evaluated during item selection. Additionally, 36,693 solutions (13.98\%) were inadmissible due to convergence issues or non-positive-definite covariance matrices. The quality of the best solutions ranged from 1.50 to 1.59 , and the best solution was found in only one run. Figure 1 shows the network of item selection frequencies, where the edges indicate how often two items were selected together across the 25 runs.

Of the 57 items, 26 were not selected in any run (omitted from Figure 1), 16 were selected in at least half of the 25 solutions, and 6 were selected in at least 23 runs. Overall, the average pairwise Jaccard distance between the 25 runs was $0.448(S D=0.171)$. This, in combination with the absence of disjointed clusters in the network structure, indicates homogeneity among the items assessing the same dimensional definition of those facets. A relatively smooth search space ensued, with multiple combinations of the same group of items leading to similarly good overall scale qualities.
Table 1. Correlations of the three facets of altruistic behaviors (FAB) subscale scores with civil courage (CC) and the KSE-G short scale

\begin{tabular}{|c|c|c|c|c|c|c|}
\hline & $M$ & $S D$ & $H G$ & $\mathrm{MC}$ & PP & $\mathrm{CC}$ \\
\hline $\mathrm{HG}$ & 3.71 & 0.87 & & & & \\
\hline MC & 3.88 & 0.85 & $.41 * *$ & & & \\
\hline PP & 3.59 & 0.85 & $.20 * *$ & $.42 \star \star$ & & \\
\hline CC & 3.93 & 0.98 & $.61 * *$ & $.62^{\star *}$ & $.41 * *$ & \\
\hline KSE-G & 4.34 & 0.74 & $.34^{* *}$ & .03 & -.09 & $.24^{\star}$ \\
\hline
\end{tabular}

Note. $\mathrm{HG}=$ help-giving; $\mathrm{MC}=$ moral courage; $\mathrm{PP}=$ peer punishment; $\mathrm{KSE}-\mathrm{G}=$ Kurzskala für soziale Erwünschtheit-Gamma. ${ }^{*} p<.05,{ }^{* *} p<.01$.

\section{Properties of the Constructed Scale}

The overall best solution with $\varphi=1.593$ was found in one run, with 21 replications within that run. This overall best solution showed excellent model fit (RMSEA $=.023$, SRMR $=.046$, and CFI $=.986$ ) with none of the descriptive fit indices violating the cut-off criteria recommended by $\mathrm{Hu}$ and Bentler (1999), and the $\chi^{2}$-test not rejecting the model $\left(\chi^{2}=100.075, d f=87, p=.160\right)$.

Figure 2 provides an overview of the selected items and the path model of the final solution. The composite reliability of the scale was $\omega=.853$.

Table 1 displays mean, standard deviations, and bivariate correlations of the final subscales with the civil courage and the KSE-G short scale. 
Table 2. Testing for factorial (measurement and structural) invariance across both samples

\begin{tabular}{lccccccccccc}
\hline Model & $\chi^{2}(d f)$ & $p$ & RMSEA & CFI & Mc & BIC & AIC & $\Delta \chi^{2}(d f)$ & $\Delta p$ & $\Delta C F I$ & $\Delta M c$ \\
\hline 1. Configural & $238.550(174)$ & $<.001$ & 0.035 & 0.972 & 0.961 & 36,707 & 36,254 & & & & \\
2. Weak & $252.156(186)$ & $<.001$ & 0.034 & 0.971 & 0.960 & 36,644 & 36,247 & $13.417(12)$ & .339 & -.001 & -.001 \\
3. Strong & $270.308(198)$ & $<.001$ & 0.034 & 0.969 & 0.957 & 36,580 & 36,241 & $18.944(12)$ & .090 & -.002 & -.003 \\
4. Strict & $286.256(213)$ & $<.001$ & 0.034 & 0.969 & 0.956 & 36,504 & 36,236 & $16.442(15)$ & .353 & -.001 & -.001 \\
5. Full & $302.481(222)$ & $<.001$ & 0.034 & 0.966 & 0.952 & 36,464 & 36,238 & $16.608(9)$ & .055 & -.003 & -.004 \\
\hline
\end{tabular}

Note. Model comparisons were performed using the Satorra-Bentler-corrected $\chi^{2}$ (Satorra \& Bentler, 2001) due to the MLM estimation used to account for non-normality of the observed variables. CFI = comparative fit index; RMSEA = root mean square error of approximation; Mc = McDonald's centrality index; $A I C=$ Akaike information criteria; $B I C=$ Bayesian information criteria; $\Delta C F I=$ differences in $C F I ; \Delta M c=$ differences in $M c$.

\section{Discussion}

The ACO produced a three-factorial model with excellent fit, contrary to classical item analysis, which did not yield a satisfactory solution (see ESM 1, Section 1.2). Importantly, only the "caring" and "befriending" factors Help-Giving showed a significant correlation with social desirability (KSE-G), while the two confrontational facets did not. To conceptually replicate and extend this finding, we used another measure of interpersonal care in Study 2, namely the Inclusion of Others in Self (IOS) scale (Aron et al., 1992).

\section{Study 2}

We presented the 15-item scale constructed in Study 1 to a new sample of participants. Using multigroup confirmatory factor analysis, we investigated the degree of measurement and structural invariance of the scale across these two independent samples.

\section{Method}

\section{Participants}

Four hundred forty participants with a mean age of 43.9 years ( $S D=15.0$; range: $18-74$ years), $55 \%$ female, filled out the survey online as part of another study (not reported here). They were recruited by a commercial panel provider. Again, the German sample was quoted in terms of age, gender, and education. Participants gave informed consent and received $€ 2.20$ for participation.

\section{Materials}

As part of the other study (see https://aspredicted.org/ blind.php? $\mathrm{x}=\mathrm{aa} 5 \mathrm{wn} 4$, a German translation of the 15-item Free Will Inventory (FWI, part I; Nadelhoffer et al., 2014), as well as some additional questions on religiosity and spirituality, were administered to participants before the 15-item FAB scale and two attentional control questions. One item of the IOS was presented as a set of seven Venn- like diagrams showing two circles overlapping to different degrees. Participants were asked to choose the diagram that best describes their relationship to "other people in general."

\section{Procedure}

The survey was implemented using Unipark EFS Survey (Version 18.4, 2018, Questback GmbH). Participants were first asked to indicate gender, age, and highest educational level to ensure proper quoting. Next, items of the FWI were presented in randomized order, followed by the items of the FAB scale in randomized order and the IOS item. Answering the survey took nine minutes on average.

\section{Statistical Analyses}

Measurement invariance across both samples was tested using the forward approach (with sequential constraint imposition) in the framework of multigroup confirmatory factor analysis (Dimitrov, 2010). We compared models with increasing restrictions on equality across the samples stepwise, considering likelihood-ratio test $\Delta \chi^{2}$, differences in terms of CFI $(\Delta \mathrm{CFI})$, as well as information criteria AIC and BIC. In addition to these preregistered criteria, we also report McDonald's Centrality Index (Mc) below. Values of $\Delta \mathrm{CFI} \geq-.01$ and $\Delta \mathrm{Mc} \geq-.02$ indicated no substantial decrease in model fit. Again, measurement models were estimated using lavaan (Version 0.6-3; Rosseel, 2012).

\section{Results}

Analyses have been preregistered at https://aspredicted. org/gm3pf.pdf. Multigroup confirmatory factor analysis was used to test for measurement invariance between the samples of Study 1 and Study 2. Table 2 displays model fit indices and model comparison criteria. The model fit of the configural model without any restrictions across samples was considered acceptable for further model comparisons with CFI $=.972$, RMSEA $=.035$, SRMR $=.046$, $\chi^{2}(174)=238.550, p<.001$. To assess measurement invariance, we consecutively compared model fit from Model 1 (configural invariance) to Model 4 (strict invariance). As 
Table 3. Means (M), standard deviations (SD), and correlations of the facets of altruistic behaviors (FAB) subscales with inclusion of others in self (IOS)

\begin{tabular}{lcclll}
\hline & $M$ & $S D$ & $H G$ & $M C$ & $P P$ \\
\hline$H G$ & 3.82 & 0.80 & & & \\
$M C$ & 3.95 & 0.84 & $.45 * *$ & & \\
PP & 3.76 & 0.87 & $.20 * *$ & $.53 * \star$ & \\
IOS & 3.59 & 1.59 & $.38 * *$ & .09 & .04 \\
\hline
\end{tabular}

Note. $H G=$ help-giving; $M C=$ moral courage; $P P=$ peer punishment ${ }^{\star} p<.05 ;{ }^{*} p<.01$; uncorrected for multiple comparisons.

model fit did not decrease substantially regarding $\chi^{2}$ and CFI, and both BIC and AIC were always smaller for the more restricted model, strict invariance of the measurement model across the two samples was assumed. The measurement properties of the FAB scale were thus reasonably equal for the two samples. Subsequently, we estimated Model 5, which tests for invariance at factor level by assuming the equality of latent means, variances and covariances across the two samples. All indicators, except for the AIC, implied a preference for Model 5 over Model $4\left(\Delta \chi^{2}=\right.$ $16.608, \Delta d f=9, \Delta p=.055, \Delta \mathrm{CFI}=-.003)$. The model with full invariance fit the data adequately with $\mathrm{CFI}=.966$, RMSEA $=.034$, SRMR $=.057$.

Means, standard deviations, and Pearson correlations of all measures used in this study are displayed in Table 3.

\section{Discussion}

Analyses in Study 2 fully confirmed the structure of the scale described in Study 1. In view of the excellent fit indices obtained and their insignificant changes as we progressively increased parameter constraints, we can assume configural invariance, measurement invariance, and structural invariance between the two samples (Dimitrov, 2010). This high degree of concordance was achieved even though the FAB scale was presented in a different study context, this time after presenting another, unrelated questionnaire, which confirms our assumption that the underlying factorial structure is robust. We conclude that the three-factorial solution depicted in Figure 1 can be generalized across samples and, given that our two samples were quoted may even be representative of the German population.

The IOS item showed covariation patterns similar to the KSE-G scale used in Study 1 while being less transparent. It correlated positively with the "tend to befriend" factor Help-Giving, but not with the two confrontational factors Moral Courage and Altruistic Peer Punishment. As IOS is known to correlate highly with empathy (Cialdini et al., 1997), the main proximate motivation for help-giving, the finding may be seen as the first step towards construct validation.

\section{Study 3}

In a pilot study, we examined the criterion validity of the three FAB subscales. We used economic game decisions for this purpose. Dictator Game contributions were seen as indicative of the propensity to help-give (Cornelissen et al., 2011; Engel, 2011; Epstein et al., 2016; Hilbig \& Zettler, 2009; Zhao et al., 2016). Investments into punishing unfair players in a public goods game were taken as behavioral probes for peer punishment (Fehr \& Gächter, 2002; Ostrom et al., 1992; Peysakhovich et al., 2014). We found no economic game in the literature that measures moral courage as defined here. What came closest is the expression of moral anger as third party observer (Baumert et al., 2013b; Halmburger et al., 2015) and behavioral opposition against ethical violations shown by a group or authority figure (Bocchiaro et al., 2012; Niesta Kayser et al., 2010), based on which we generated a novel game scenario.

Preregistrations can be found at https://aspredicted.org/ vu6ds.pdf and https://aspredicted.org/u8pa7.pdf. Data and scripts are available from the "Data and scripts paper" folder at https://osf.io/jvp84/.

\section{Methods}

A total of 68 participants (63\% female, $0 \%$ diverse, $75 \%$ students, aged $M=29.87, S D=13.57$, range: $19-75)$ completed two parts of a study that involved the FAB shortscale online upon recruitment, and the economic games in another online session, conducted approximately two weeks later to counter potential transfer effects. As instructions to one of the games were changed during data acquisition (see "Third-Party Intervention" below), data of only 30 participants were available for that particular game.

The economic games were presented in randomized order. The games were not incentivized (no real money was paid out) but designed to appear as realistic as possible (e.g., brief pauses simulated that other players were contemplating). Participants were told upfront that no real money was at stake and that payoffs were fictitious. They were fully debriefed after the experiment that the other participants were staged in all games. In the "Dictator Game," participants were told that they were randomly selected as winners of a reward of $€ 10.70$. They were given two options: they could keep the money or share the amount (freely) with another participant who had not been chosen to receive a reward. In the "Public Goods Game with punishment option," participants played in groups of four pursuing an investment project. With an initial endowment of $€ 5$, they were asked to invest in the project. The sum of all contributions would then be tripled and distributed to all members in equal shares. Participants made 
Table 4. Descriptive statistics and Pearson correlations for pilot validation Study 1 with $N=68$

\begin{tabular}{|c|c|c|c|c|c|c|c|}
\hline Variable & M & $S D$ & $1 \mathrm{HG}$ & $2 \mathrm{MC}$ & $3 \mathrm{PP}$ & $4 \mathrm{DG}^{\mathrm{a}}$ & $5 \mathrm{TP}^{\mathrm{bc}}$ \\
\hline 1. $H G$ & 4.07 & 0.68 & & & & & \\
\hline 2. $M C$ & 4.02 & 0.73 & .08 & & & & \\
\hline 3. PP & 3.43 & 0.96 & -.04 & $.40 * \star$ & & & \\
\hline 4. DG giving ${ }^{a}$ & 3.79 & 2.63 & $.40 * *$ & .05 & -.16 & & \\
\hline 5. TP intervention ${ }^{\mathrm{bc}}$ & 0.63 & 0.49 & -.21 & $.37 *$ & .29 & -.28 & \\
\hline 6. Punishment costs ${ }^{a}$ & 1.44 & 1.58 & .01 & .21 & $.31 * *$ & .03 & .26 \\
\hline
\end{tabular}

Note. $M=$ mean; $S D=$ standard deviation; $H G$ = help-giving; $M C=$ moral courage; PP = peer punishment; DG = Dictator Game, TP = Third Party. ${ }^{\text {S Spearman }}$ correlation coefficient was calculated because of non-normal distributions. ${ }^{b}$ Binary variable: $0=$ no and $1=y e s .{ }^{c} \mathrm{~N}=30$. Hypothesized correlations are boldfaced. ${ }^{\star} p<.05 ;{ }^{*} p<.01$.

investment decisions in three practice rounds. In the third practice round, they additionally had the option to punish unfair group members, that is, free riders who did not contribute their fair share but benefited from the investments of others. Punishment would reduce other group members' outcomes with a fee-to-fine ratio of 1:3. The fourth round was then used for data collection.

Finally, in the spirit of a pilot study, we developed a new paradigm to observe morally courageous behavior in a clearly defined game situation which we call the "ThirdParty Intervention." The logic was to determine whether participants would personally confront another player who had more power than the other players but behaved selfishly and spitefully. This player was introduced as being entitled to decide about the participant's own as well as the other players' payouts. Participants then observed that the person kept a large sum of $€ 9.40$, which could have been shared with the others, then took $€ 11.50$ from other players without justification, and indiscriminately excluded some other players from the payout. Participants were allowed to send a message to this person, who would be online, but had the power to respond to the message by excluding the participants from playing and from being paid off.

After $N=38$ datasets were collected, we found that this setup yielded larger correlations to the Peer Punishment subscale than to Moral Courage, and therefore modified some aspects to make it more distinctly reflect Moral Courage. We added the usernames of those participants who were excluded by the unfair opposer so that they sounded as if they had non-Western backgrounds, implicitly portraying them as members of minority groups. Furthermore, we presented the pseudonyms of other participants who could have sent a message to the offender but who had failed to do so, suggesting that most of the other players accepted the person's unfair behavior. We then asked participants if they wanted to send the offender a message, one that would be presented to all members of the group.

\section{Results}

As expected, the subscale Help-Giving correlated significantly with (and only with) anonymous Dictator Game giving, whereas Peer Punishment correlated significantly with (and only with) the amount of (fictitious) money spent on punishing unfair players in the Public Goods Game. Moral Courage correlated significantly (and selectively) with the decision to intervene against the offender in the Third-Party Intervention. The pattern provides preliminary evidence for the convergent and divergent criterion validity of the three subscales (Table 4).

\section{General Discussion}

The literature leaves hardly any doubt about the notion that altruism is a domain-general, stable personality trait (Hilbig et al., 2013; Peysakhovich et al., 2014; Thielmann et al., 2020). Its relevance for some of the world's most pressing problems seems undisputable (Böhm et al., 2018; van Lange et al., 2018). Here, we designed a questionnaire that may prove useful whenever altruism matters as a behavioral trait, not just a value, and represents more than just common kindness.

By performing item selection via ACO, we generated a highly reliable and very short scale, capturing three distinct facets of altruistic behaviors (FAB) with only 15 items. The scale's structural validity was confirmed by Study 2 , which yielded full invariance.

Unlike previous altruism scales (Rodrigues et al., 2017; Rushton et al., 1981), the FAB scale not only measures help-giving ( $\mathrm{HG}$ ) but additionally integrates antagonistic facets of altruistic behaviors which serve to defend locally established fairness norms (PP) or one's own moral values (MC). In the existing literature on these two constructs, we found only one self-report questionnaire designed to capture costly punishment (Peysakhovich et al., 2014) and one addressing moral courage as understood here 
(Bronstein et al., 2007)., However, psychometric properties are not known for both these scales, and the scales have apparently not been used in any other published studies. For the FAB subscales, the current study finds not only high reliability but also provides pilot information on external validity in the form of subscale-specific correlations with economic game decisions (Study 3). Convergent validity of HG was easy to corroborate by DG giving, whereas MC and PP were harder to establish, primarily because it proved difficult to design a behavioral moral courage scenario (distinct from mere punishment) without putting participants at risk or deceiving them severely.

Among the subscales, MC correlated quite highly with $\mathrm{HG}$ in all studies, as if both reflected a genuine preference for humanitarian, benevolent acting, regardless of the dangers involved. By contrast, PP was only moderately correlated with HG (.24) in Studies 1 and 2 and practically null-correlated in the pilot study. To some researchers, it may come as a surprise that the correlation was positive in the two larger assessments, despite growing doubts that costly punishment is altruistically motivated (Brethel-Haurwitz et al., 2016; Rodrigues et al., 2020). After all, the act of punishment seems vengeful and hostile from a proximate viewpoint. However, it must be kept in mind, that the $\mathrm{FAB}$ items have intentionally been based on an effect-based definition of altruism, regardless of the underlying motives and experiences. Behavior can be egoistically motivated while being objectively altruistic and vice versa (Slote, 2013; Wilson, 1992). What counts for the objective assessment of PP is only that punishers initiate or otherwise invest into controlling and sanctioning unfair others via punitive measures without being able to request apposite reimbursement for their expenditures.

That said, we concede that peer punishment is certainly less open-minded and generous than it is helping. However, it is also less costly and risky, at least the way we operationalized it. While HG items describe genuinely selfless acts mostly under anonymous conditions, of which some are extreme, punishment behaviors are indirect, hidden, and usually backed up by the peer group. However, considering that the correlation of MC with PP was relatively high in Studies 1 and 2 (around .50), even though only moral courage involves high risk while peer punishment does not, we suspect that it may indeed be the offensive undertone rather than the (differential) risk component that accounts for the divergence between PP and HG. At present, this must remain speculative, but the latent motives underlying the three facets of altruistic behavioral traits will be among the most interesting questions that research can address with the FAB once it has been validated more extensively.

In describing altruistic behaviors as opposed to values or attitudes, we expected the $\mathrm{FAB}$ to be relatively resistant against socially desirable responses. We found that the correlations between FAB and KSE-G scores were nonsignificant for PP and MC and only .34 for HG, suggesting that MC and PP are not considered to attract much social approval. Interestingly, the less transparent IOS item used in Study 2 showed a similar pattern: a medium-sized correlation with $\mathrm{HG}$ and no significant correlation with either PP or MC. Thus, individuals with higher experienced overlap between themselves and others report more helping, but they do not report engaging more in confrontative forms of altruistic behaviors. One explanation could be that PP and $\mathrm{MC}$, relative to the other-befriending HG trait, require a higher degree of autonomy and independence from others, even though all three behaviors are effectively other-concerned.

The correlational pattern of our self-designed Civil Courage (CC) scale with the FAB subscales suggests that other-orientation may be universal in $\mathrm{HG}$ and $\mathrm{MC}$, which showed positive correlations instead of ingroup-related (parochial) in PP, which did not show a significant correlation. CC was defined here as courageous acting in defense of civil-democratic values, in line with humanitarian ideals. The correlation of CC with MC depends on the proportion of democratically-minded individuals in the sample. The two scales will dissociate ( $=$ not correlate significantly) in a sample of participants with non-democratic values, who will score low on CC, yet potentially high on MC. In our sample, the correlation was .62 (theoretically .68, if corrected for the limited reliability of the two subscales), which is high, albeit in the same range as the correlation of MC with HG. This is an important result because it defies the potential criticism that some of our MC items describe egoistic acts. We highlight again that the MC scale alone is oblivious to the values that are being defended. What counts is that these values are meant to apply to all people or society as a whole and are thus other-concerned. Put bluntly, a religious fundamentalist who is willing to fight for their ideology while sacrificing much if not all of their well-being, would score high on MC but low on CC, and may be identifiable by this pattern (cf. Kossowska et al., 2018).

The FAB scale may prove useful in profiling altruistic traits among political, organizational, cultural, and other groups in research contexts. Scientists from the domain of economic and evolutionary game theory have complained about the failure of psychology to contribute valid trait measures of altruism and prosociality for large-scale assessments. For example, Henrich (2015) notes: "Disciplines like psychology, neuroscience and economics are not well equipped, either theoretically or institutionally, to deal with population-level psychological and neurological differences" (p. 86). Likewise, Epstein et al. (2016) write: "We observe that the combination of a variety of survey measures related to personality and morality, as well as a 
wide range of demographics, do quite poorly at predicting participants' cooperative type" (p. 556). We hope that the FAB scale will fill this gap to facilitate the kinds of intercultural and intergenerational comparisons that can at present be performed only based on expensive and intricate economic game designs (Ensminger \& Henrich, 2014; Marlowe et al., 2008), while providing only binary measures in many cases, and leaving MC out entirely.

In practical regards, the $\mathrm{FAB}$ scale might help in career counseling and task placement after appropriate empirical testing through further research. The field of organizational psychology has long recognized that prosocial behaviors are no mere opposites to business making (e.g., Grant \& Berg, 2012). High help-giving is essential for jobs providing care and support, though burnout needs to be prevented (Zellars et al., 2000). Authentic leadership almost certainly requires high moral courage (Hannah et al., 2011). A combination of both helping and punishment preferences characterize police service candidates (Friebel et al., 2019), and the same appears to be true for teachers (Newby, 1991).

Before real-world applications, however, it would be necessary to further construct-validate the subscales of the FAB scale using established personality concepts, including honesty-humility, agreeableness, and selfishness (e.g., Diebels et al., 2018). The first step into this direction is another pilot study of ours with $N=89$ individuals in which we found a correlation of .33 with SVO (Murphy \& Ackermann, 2014) and .64 with the Rushton scale (Rushton et al., 1981; see ESM 1, Section 1.6). However, it must not be forgotten that despite its focus on behaviors, the FAB scale is still a self-report scale. On the one hand, the FAB scale may be less transparent than existing scales of prosociality and altruism due to the integration of antagonistic behaviors, involving items such as "It has happened that I have affronted others due to my moral convictions". On the other hand, it nonetheless only describes actions without testing for these. Future investigations will need to examine the problem of biased responding, perhaps by contrasting extreme altruists (Brethel-Haurwitz et al., 2016; Kossowska et al., 2018; Rand \& Epstein, 2014) with clear-cut selfish individuals (Diebels et al., 2018; Raine \& Uh, 2019).

In summary, we have shown the construction of the FAB scale using a novel algorithmic item selection approach that outperformed classical item selection procedures. The scale measures three different types of altruistic behavioral traits that are distinct but not uncorrelated. Its structural invariance across two German samples was demonstrated. In addition to being highly consistent, the FAB is highly cost-efficient and takes only a few minutes to administer. These features make it valuable for screening purposes and large-scale assessments, in addition to individual diagnostics, after further validation and standardization.

\section{Electronic Supplementary Material}

The electronic supplementary material is available with the online version of the article at https://doi.org/10.1027/ 1864-9335/a000460

ESM 1. The file contains information on (1) the process of item generation and the definition of the three facets, (2) classical item construction, (3) Exploratory Structural Equation Modeling (ESEM) to investigate the FABs factorial structure, (4) wording and selection of civil courage items, (5) additional questions asked in the survey about the items, and (6) methods and results of another pilot study on construct validity.

\section{References}

Andreoni, J., Harbaugh, W. T., \& Vesterlund, L. (2010). Altruism in experiments. In S. N. Durlauf \& L. E. Blume (Eds.), Behavioural and experimental economics (pp. 6-13). Palgrave Macmillan UK. https://doi.org/10.1057/9780230280786_2

Aron, A., Aron, E. N., \& Smollan, D. (1992). Inclusion of other in the self scale and the structure of interpersonal closeness. Journal of Personality and Social Psychology, 63(4), 596-612. https:// doi.org/10.1037/0022-3514.63.4.596

Batson, C. D. (2010). The naked emperor: Seeking a more plausible genetic basis for psychological altruism. Economics and Philosophy, 26(2), 149-164. https://doi.org/10.1017/ S0266267110000179

Batson, C. D., Ahmad, N., Powell, A. A., \& Stocks, E. L. (2008). Prosocial motivation. In J. Y. In Shah \& W. L. Gardner (Eds.), Handbook of motivation science (pp. 135-149). The Guilford Press.

Batson, C. D., Duncan, B. D., Ackerman, P., Buckley, T., \& Birch, K. (1981). Is empathic emotion a source of altruistic motivation? Journal of Personality and Social Psychology, 40(2), 290-302. https://doi.org/10.1037/0022-3514.40.2.290

Baumert, A., Halmburger, A., \& Schmitt, M. (2013). Interventions against norm violations: Dispositional determinants of selfreported and real moral courage. Personality and Social Psychology Bulletin, 39(8), 1053-1068. https://doi.org/ 10.1177/0146167213490032

Baumert, A., Halmburger, A., \& Schmitt, M. (2013). Interventions against norm violations: Dispositional determinants of selfreported and real moral courage. Personality and Social Psychology Bulletin, 39(8), 1053-1068. https://doi.org/ 10.1177/0146167213490032

Bentler, P. M. (1990). Comparative fit indexes in structural models. Psychological Bulletin, 107(2), 238-246. https://doi. org/10.1037/0033-2909.107.2.238

Bishara, A. J., \& Hittner, J. B. (2015). Reducing bias and error in the correlation coefficient due to nonnormality. Educational and Psychological Measurement, 75(5), 785-804. https://doi. org/10.1177/0013164414557639

Bocchiaro, P., Zimbardo, P. G., \& Van Lange, P. A. M. (2012). To defy or not to defy: An experimental study of the dynamics of disobedience and whistle-blowing. Social Influence, 7(1), 35-50. https://doi.org/10.1080/15534510.2011.648421

Böhm, R., Theelen, M. M., Rusch, H., \& Van Lange, P. A. (2018). Costs, needs, and integration efforts shape helping behavior toward refugees. Proceedings of the National Academy of Sciences, 115(28), 7284-7289. https://doi.org/10.1073/pnas.1805601115 
Boyd, R., Gintis, H., \& Bowles, S. (2010). Coordinated punishment of defectors sustains cooperation and can proliferate when rare. Science, 328(5978), 617-620. https://doi.org/10.1126/ science.1183665

Boyd, R., Gintis, H., Bowles, S., \& Richerson, P. J. (2003). The evolution of altruistic punishment. Proceedings of the National Academy of Sciences, 100(6), 3531-3535. https://doi.org/ 10.1073/pnas.0630443100

Brethel-Haurwitz, K. M., Stoycos, S. A., Cardinale, E. M., Huebner, B., \& Marsh, A. A. (2016). Is costly punishment altruistic? Exploring rejection of unfair offers in the Ultimatum Game in real-world altruists. Scientific Reports, 6(1), 1-10. https://doi. org/10.1038/srep18974

Bronstein, P., Fox, B. J., Kamon, J. L., \& Knolls, M. L. (2007). Parenting and gender as predictors of moral courage in late adolescence: A longitudinal study. Sex Roles, 56(9), 661-674. https://doi.org/10.1007/s11199-007-9182-8

Cialdini, R. B., Brown, S. L., Lewis, B. P., Luce, C., \& Neuberg, S. L. (1997). Reinterpreting the empathy-altruism relationship: When one into one equals oneness. Journal of Personality and Social Psychology, 73(3), 481-484. https://doi.org/10.1037/ 0022-3514.73.3.481

Cornelissen, G., Dewitte, S., \& Warlop, L. (2011). Are social value orientations expressed automatically? Decision making in the dictator game. Personality and Social Psychology Bulletin, 37(8), 1080-1090. https://doi.org/10.1177/0146167211405996

Darley, J. M., \& Latané, B. (1968). Bystander intervention in emergencies: Diffusion of responsibility. Journal of Personality and Social Psychology, 8(4), 377-383. https://doi.org/10.1037/ h0025589

Diebels, K. J., Leary, M. R., \& Chon, D. (2018). Individual differences in selfishness as a major dimension of personality: A reinterpretation of the sixth personality factor. Review of General Psychology, 22(4), 367-376. https://doi.org/10.1037/ gpr0000155

Dimitrov, D. M. (2010). Testing for factorial invariance in the context of construct validation. Measurement and Evaluation in Counseling and Development, 43(2), 121-149. https://doi.org/ $10.1177 / 0748175610373459$

Dorigo, M., \& Stützle, T. (2010). Ant colony optimization: Overview and recent advances. In M. Gendreau \& J. Y. Potvin (Eds.), Handbook of metaheuristics (pp. 227-263). Springer. https:// doi.org/10.1007/978-1-4419-1665-5_8

Dreber, A., Rand, D. G., Fudenberg, D., \& Nowak, M. A. (2008). Winners don't punish. Nature, 452(7185), 348-351. https://doi. org/10.1038/nature06723

Dungan, J. A., Young, L., \& Waytz, A. (2019). The power of moral concerns in predicting whistleblowing decisions. Journal of Experimental Social Psychology, 85, Article 103848. https://doi. org/10.1016/j.jesp. 2019.103848

Engel, C. (2011). Dictator games: A meta study. Experimental Economics, 14(4), 583-610. https://doi.org/10.1007/s10683011-9283-7

Ensminger, J., \& Henrich, J. (2014). Experimenting with social norms: Fairness and punishment in cross-cultural perspective. Russell Sage Foundation.

Epstein, Z., Peysakhovich, A., \& Rand, D. G. (2016). The good, the bad, and the unflinchingly selfish: Cooperative decision-making can be predicted with high accuracy when using only three behavioral types. Proceedings of the 2016 ACM Conference on Economics and Computation, 547-559. https://doi.org/10. $1145 / 2940716.2940761$

Fehl, K., Sommerfeld, R. D., Semmann, D., Krambeck, H.-J., \& Milinski, M. (2012). I dare you to punish me - Vendettas in games of cooperation. PLoS One, 7(9), Article e45093. https:// doi.org/10.1371/journal.pone.0045093
Fehr, E., \& Fischbacher, U. (2003). The nature of human altruism. Nature, 425(6960), 785-791. https://doi.org/10.1038/nature02043

Fehr, E., \& Fischbacher, U. (2004). Third-party punishment and social norms. Evolution and Human Behavior, 25(2), 63-87. https://doi.org/10.1016/S1090-5138(04)00005-4

Fehr, E., \& Gächter, S. (2002). Altruistic punishment in humans. Nature, 415(6868), 137-140. https://doi.org/10.1038/415137a

Fehr, E., \& Rockenbach, B. (2003). Detrimental effects of sanctions on human altruism. Nature, 422(6928), 137-140. https:// doi.org/10.1038/nature01474

Feinberg, M., Willer, R., \& Schultz, M. (2014). Gossip and ostracism promote cooperation in groups. Psychological Science, 25(3), 656-664. https://doi.org/10.1177/0956797613510184

Fischer, P., Krueger, J. I., Greitemeyer, T., Vogrincic, C., Kastenmüller, A., Frey, D., Heene, M., Wicher, M., \& Kainbacher, M. (2011). The bystander-effect: A meta-analytic review on bystander intervention in dangerous and non-dangerous emergencies. Psychological Bulletin, 137(4), 517-537. https:// doi.org/10.1037/a0023304

Friebel, G., Kosfeld, M., \& Thielmann, G. (2019). Trust the police? Self-selection of motivated agents into the German police force. American Economic Journal: Microeconomics, 11(4), 59-78. https://doi.org/10.1257/mic.20170389

Gintis, H. (2011). Gene-culture coevolution and the nature of human sociality. Philosophical Transactions of the Royal Society B: Biological Sciences, 366(1566), 878-888. https://doi.org/ 10.1098/rstb.2010.0310

Grant, A. M., \& Berg, J. M. (2012). Prosocial motivation. In F. J. Lara (Ed.), The Oxford handbook of positive organizational scholarship (pp. 28-44). Oxford University Press.

Gross, J., Méder, Z. Z., Okamoto-Barth, S., \& Riedl, A. (2016). Building the leviathan-voluntary centralisation of punishment power sustains cooperation in humans. Scientific Reports, 6(1), 1-9. https://doi.org/10.1038/srep20767

Guala, F. (2010). Reciprocity: Weak or strong? What punishment experiments do (and do not) demonstrate (Working Paper No. 23). University of Milan Department of Economics, Business and Statistics. https://doi.org/10.1017/S0140525×11000069

Halmburger, A., Baumert, A., \& Schmitt, M. (2015). Anger as driving factor of moral courage in comparison with guilt and global mood: A multimethod approach. European Journal of Social Psychology, 45(1), 39-51. https://doi.org/10.1002/ejsp.2071

Halmburger, A., Baumert, A., \& Schmitt, M. (2017). Everyday heroes: Determinants of moral courage. In S. T. Allison, G. R. Goethals, \& R. M. Kramer (Eds.), Handbook of heroism and heroic leadership (pp. 165-184). Routledge/Taylor \& Francis Group.

Hannah, S. T., Avolio, B. J., \& Walumbwa, F. O. (2011). Relationships between authentic leadership, moral courage, and ethical and pro-social behaviors. Business Ethics Quarterly, 21(4), 555-578. https://doi.org/10.5840/beq201121436

Henrich, J. (2015). Culture and social behavior. Current Opinion in Behavioral Sciences, 3, 84-89. https://doi.org/10.1016/ j.cobeha.2015.02.001

Hilbig, B. E., \& Zettler, I. (2009). Pillars of cooperation: Honestyhumility, social value orientations, and economic behavior. Journal of Research in Personality, 43(3), 516-519. https://doi. org/10.1016/j.jrp.2009.01.003

Hilbig, B. E., Zettler, I., Leist, F., \& Heydasch, T. (2013). It takes two: Honesty-Humility and Agreeableness differentially predict active versus reactive cooperation. Personality and Individual Differences, 54(5), 598-603. https://doi.org/10.1016/j.paid. 2012.11.008

Hu, L., \& Bentler, P. M. (1999). Cutoff criteria for fit indexes in covariance structure analysis: Conventional criteria versus new alternatives. Structural Equation Modeling: A Multidisciplinary Journal, 6(1), 1-55. https://doi.org/10.1080/10705519909540118 
Janssen, A. B., Schultze, M., \& Grötsch, A. (2017). Following the ants: Development of short scales for proactive personality and supervisor support by ant colony optimization. European Journal of Psychological Assessment, 33(6), 409-421. https:// doi.org/10.1027/1015-5759/a000299

Jonas, K. J., \& Brandstatter, V. (2004). Moral courage: Definition, findings, and interventions. Zeitschrift für Sozialpsychologie, 35(4), 185-200. https://doi.org/10.1024/0044-3514.35.4.185

Kastenmüller, A., Greitemeyer, T., Fischer, P., \& Frey, D. (2007). The Munich Civil Courage Instrument (MuZI): Development and validation. Diagnostica, 53(4), 205-217. https://doi.org/ 10.1026/0012-1924.53.4.205

Kemper, C. J., Beierlein, C., Bensch, D., Kovaleva, A., \& Rammstedt, B. (2012). Eine Kurzskala zur Erfassung des GammaFaktors sozial erwünschten Antwortverhaltens: Die Kurzskala Soziale Erwünschtheit-Gamma (KSE-G) [A short scale for assessment of the gamma factor of socially desirable response behavior: The Social Desirability Short Scale]. GESIS-Working Papers, 2012(25), 27. https://nbn-resolving.org/urn:nbn: de:0168-ssoar-339589

Kerr, B., Godfrey-Smith, P., \& Feldman, M. W. (2004). What is altruism? Trends in Ecology \& Evolution, 19(3), 135-140. https://doi.org/10.1016/j.tree.2003.10.004

Kinnunen, S. P., \& Windmann, S. (2013). Dual-processing altruism. Frontiers in Psychology, 4, Article 193. https://doi.org/10.3389/ fpsyg.2013.00193

Kinnunen, S., Singh, M., \& Windmann, S. (2015). Dissociating facets of self-reported altruism in India and Germany: Preliminary evidence. Psychological Studies, 60(2), 193-203. https:// doi.org/10.1007/s12646-015-0309-7

Kossowska, M., Szwed, P., Wyczesany, M., Czarnek, G., \& Wronka, E. (2018). Religious fundamentalism modulates neural responses to error-related words: The role of motivation toward closure. Frontiers in Psychology, 9, Article 285. https://doi.org/ 10.3389/fpsyg.2018.00285

Landmann, H., \& Hess, U. (2017). What elicits third-party anger? The effects of moral violation and others' outcome on anger and compassion. Cognition and Emotion, 31(6), 1097-1111. https://doi.org/10.1080/02699931.2016.1194258

Leite, W. L., Huang, I.-C., \& Marcoulides, G. A. (2008). Item selection for the development of short forms of scales using an ant colony optimization algorithm. Multivariate Behavioral Research, 43(3), 411-431. https://doi.org/10.1080/00273170802285743

Luo, Y., Shuster, A., Chung, D., O'Brien, M., Heflin, M., Perl, O., Kulkarni, K., Na, S., Fiore, V. G., Montague, P. R., \& Gu, X. (2021). Altruism in a time of crisis: Dissociable social valuation and perception during COVID-19 in the United States. PsyArXiv. https://doi.org/10.31234/osf.io/kb9tu

Marlowe, F. W., Berbesque, J. C., Barr, A., Barrett, C., Bolyanatz, A., Cardenas, J. C., Ensminger, J., Gurven, M., Gwako, E., Henrich, J., Henrich, N., Lesorogol, C., McElreath, R., \& Tracer, D. (2008). More "altruistic" punishment in larger societies. Proceedings of the Royal Society B: Biological Sciences, 275 (1634), 587-592. https://doi.org/10.1098/rspb.2007.1517

Mayr, E. (1961). Cause and effect in biology. Science, 134(3489), 1501-1506. https://www.jstor.org/stable/1707986

McDonald, R. P. (1999). Test theory: A unified treatment. Erlbaum.

Molleman, L., Kölle, F., Starmer, C., \& Gächter, S. (2019). People prefer coordinated punishment in cooperative interactions. Nature Human Behaviour, 3(11), 1145-1153. https://doi.org/ 10.1038/s41562-019-0707-2

Murphy, R. O., \& Ackermann, K. A. (2014). Social value orientation: Theoretical and measurement issues in the study of social preferences. Personality and Social Psychology Review, 18(1), 13-41. https://doi.org/10.1177/1088868313501745
Nadelhoffer, T., Shepard, J., Nahmias, E., Sripada, C., \& Ross, L. T. (2014). The free will inventory: Measuring beliefs about agency and responsibility. Consciousness and Cognition, 25, 27-41. https://doi.org/10.1016/j.concog.2014.01.006

Newby, T. J. (1991). Classroom motivation: Strategies of first-year teachers. Journal of Educational Psychology, 83(2), 195-200. https://doi.org/10.1037/0022-0663.83.2.195

Niesta Kayser, D., Greitemeyer, T., Fischer, P., \& Frey, D. (2010). Why mood affects help giving, but not moral courage: Comparing two types of prosocial behaviour. European Journal of Social Psychology, 40(7), 1136-1157. https://doi.org/10.1002/ ejsp.717

Nikiforakis, N., \& Engelmann, D. (2011). Altruistic punishment and the threat of feuds. Journal of Economic Behavior \& Organization, 78(3), 319-332. https://doi.org/10.1016/j.jebo.2011.01.017

Olaru, G., Schroeders, U., Wilhelm, O., \& Ostendorf, F. (2018). A confirmatory examination of age-associated personality differences: Deriving age-related measurement-invariant solutions using ant colony optimization. Journal of Personality, 86(6), 1037-1049. https://doi.org/10.1111/jopy.12373

Ostrom, E., Walker, J., \& Gardner, R. (1992). Covenants with and without a sword: Self-governance is possible. American Political Science Review, 86(2), 404-417. https://doi.org/10.2307/1964229

Perc, M. (2012). Sustainable institutionalized punishment requires elimination of second-order free-riders. Scientific Reports, 2(1), 1-6. https://doi.org/10.1038/srep00344

Peysakhovich, A., Nowak, M. A., \& Rand, D. G. (2014). Humans display a "cooperative phenotype" that is domain general and temporally stable. Nature Communications, 5(1), 1-8. https:// doi.org/10.1038/ncomms5939

Pfattheicher, S., \& Keller, J. (2017). A motivational perspective on punishment in social dilemmas. European Review of Social Psychology, 28(1), 257-287. https://doi.org/10.1080/10463283. 2017.1375662

R Core Team. (2019). R: A language and environment for statistical computing. https://www.R-project.org/

Raine, A., \& Uh, S. (2019). The Selfishness Questionnaire: Egocentric, adaptive, and pathological forms of selfishness. Journal of Personality Assessment, 101(5), 503-514. https:// doi.org/10.1080/00223891.2018.1455692

Rand, D. G., \& Epstein, Z. G. (2014). Risking your life without a second thought: Intuitive decision-making and extreme altruism. PLoS One, 9(10), Article e109687. https://doi.org/10.1371/ journal.pone.0109687

Rodrigues, J., \& Hewig, J. (2020). Let's call it altruism! A psychological perspective and hierarchical framework of altruism and prosocial behavior. Psyarxiv. https://psyarxiv.com/pj7eu/

Rodrigues, J., Liesner, M., Reutter, M., Mussel, P., \& Hewig, J. (2020). It's costly punishment, not altruistic: Low midfrontal theta and state anger predict punishment. Psychophysiology, 57(8), Article e13557. https://doi.org/10.1111/psyp.13557

Rodrigues, J., Ulrich, N., Mussel, P., Carlo, G., \& Hewig, J. (2017). Measuring prosocial tendencies in Germany: Sources of validity and reliablity of the revised prosocial tendency measure. Frontiers in Psychology, 8, Article 2119. https://doi.org/ 10.3389/fpsyg.2017.02119

Rosseel, Y. (2012). Lavaan: An R package for structural equation modeling. Journal of Statistical Software, 48(2), 1-36.

Rushton, J. P., Chrisjohn, R. D., \& Fekken, G. C. (1981). The altruistic personality and the Self-Report Altruism Scale. Personality and Individual Differences, 2(4), 293-302. https:// doi.org/0191-8869/81/040293-10102.00/0

Satorra, A., \& Bentler, P. M. (2001). A scaled difference chi-square test statistic for moment structure analysis. Psychometrika, 66(4), 507-514. https://doi.org/10.1007/BF02296192 
Schroeders, U., Wilhelm, O., \& Olaru, G. (2016). Meta-heuristics in short scale construction: Ant colony optimization and genetic algorithm. PLoS One, 11(11), Article e0167110. https://doi.org/ 10.1371/journal.pone.0167110

Schultze, M. (2017). Constructing subtests using ant colony optimization (PhD thesis). https://refubium.fu-berlin.de/handle/ fub188/2951

Schultze, M. (2018). Stuart: Subtests using algorithmic rummaging techniques. https://CRAN.R-project.org/package=stuart

Schultze, M., \& Eid, M. (2018). Automated item selection in crosscultural settings. Methodology, 14(4), 177-188. https://doi.org/ 10.1027/1614-2241/a000155

Slote, M. (2013). Egoism and emotion. Philosophia, 41(2), 313-335. https://doi.org/10.1007/s11406-013-9434-5

Steiger, J. H., \& Lind, J. C. (1980, May). Statistically based tests for the number of common factors. Paper presented at the Annual Meeting of the Psychometric Society, lowa City, IA.

Stützle, T. (1998). Local search algorithms for combinatorial problems: Analysis, improvements, and new applications (PhD thesis). Darmstadt University of Technology.

Thielmann, I., Spadaro, G., \& Balliet, D. (2020). Personality and prosocial behavior: A theoretical framework and meta-analysis. Psychological Bulletin, 146(1), 30-90. https://doi.org/10.1037/ bul0000217

Tinbergen, N. (1963). On aims and methods of ethology. Zeitschrift für Tierpsychologie, 20(4), 410-433. https://doi.org/10.1111/ j.1439-0310.1963.tb01161.x

Van Lange, P. A., Joireman, J., \& Milinski, M. (2018). Climate change: What psychology can offer in terms of insights and solutions. Current Directions in Psychological Science, 27(4), 269-274. https://doi.org/10.1177/0963721417753945

Waytz, A., Dungan, J., \& Young, L. (2013). The whistleblower's dilemma and the fairness-loyalty tradeoff. Journal of Experimental Social Psychology, 49(6), 1027-1033. https://doi.org/ 10.1016/j.jesp.2013.07.002

Wilson, D. S. (1992). On the relationship between evolutionary and psychological definitions of altruism and selfishness. Biology and Philosophy, 7(1), 61-68. https://doi.org/10.1007/Bf00130164

Wilson, D. S. (2015). Does altruism exist? Culture, genes, and the welfare of others. Yale University Press.

Wu, J., Balliet, D., \& Van Lange, P. A. (2016). Gossip versus punishment: The efficiency of reputation to promote and maintain cooperation. Scientific Reports, 6, Article 23919. https://doi.org/10.1038/srep23919

Yang, Y., \& Green, S. B. (2010). A note on structural equation modeling estimates of reliability. Structural Equation Modeling: A Multidisciplinary Journal, 17(1), 66-81. https://doi.org/ 10.1080/10705510903438963

Zellars, K. L., Perrewé, P. L., \& Hochwarter, W. A. (2000). Burnout in health care: The role of the five factors of personality. Journal of Applied Social Psychology, 30(8), 1570-1598. https://doi.org/ 10.1111/j.1559-1816.2000.tb02456.x
Zhao, K., Ferguson, E., \& Smillie, L. D. (2016). Prosocial personality traits differentially predict egalitarianism, generosity, and reciprocity in economic games. Frontiers in Psychology, 7 , Article 1137. https://doi.org/10.3389/fpsyg.2016.01137

\section{History}

Received November 27, 2020

Revision received August 26, 2021

Accepted August 27, 2021

Published online November 12, 2021

\section{Conflict of Interest}

Data collection was supported by the Leibniz Institute for Psychology Information in Trier, Germany. We have no conflict of interest to declare.

\section{Authorship}

Sabine Windmann delineated the study design, constructed the items, drafted the manuscript, and helped to analyze the data. Lucie Binder assisted in constructing the scale, collected the data, performed main portions of data analysis, and helped with paper writing. Martin Schultze helped conceptualize the studies methodologically, analyze the data, visualize the results, and helped writing the manuscript.

\section{Open Data}

Open Science has been practiced throughout. Study 1 has been preregistered at https://osf.io/2buh6, Study 2 at https://aspredicted. org/gm3pf.pdf, and Study 3 at https://aspredicted.org/vu6ds.pdf and https://aspredicted.org/u8pa7.pdf

Data and scripts are fully available at https://osf.io/jvp84/ (for Studies 1, 2 and 3).

\section{Funding}

Open access publication enabled by the University Library Johann Christian Senckenberg.

\section{ORCID}

Sabine Windmann

(D) https://orcid.org/0000-0002-3573-7526

\section{Sabine Windmann}

Department of Psychology

Goethe University

Theodor-W.-Adorno Platz 6

60323 Frankfurt/Main

Germany

s.windmann@psych.uni-frankfurt.de 


\section{Appendix}

Table A1. Original version of the 15 selected facets of altruistic behaviors (FAB) items and the five selected civil courage items

PP_1 Wenn sich einzelne Personen Sonderrechte herausnehmen, suche ich nach Verbündeten, um diese Person auszubremsen.

PP_8 Wenn jemand die Gemeinschaft absichtlich ausnützt, revanchiere ich mich diskret auf irgendeine Weise.

PP_12 Ich beobachte genau, ob sich jemand im Team daneben benimmt.

PP_14 Wenn sich eine Person auf Kosten meiner Gruppe Vorteile verschafft, arbeite ich im Privaten darauf hin, dass sie damit scheitert.

PP_15 Wer die geltenden Regeln zu seinen eigenen Gunsten auslegt, wird früher oder später von mir und meinen Freunden dafür zur

HG_1 In einem Zwiespalt wende ich mich lieber den Schwachen zu als den Starken.

HG_3 Ich würde durchaus mein eigenes Wohlergehen gefährden, um hungernden und kranken Menschen zu helfen.

HG_7 Trotz der Kosten für mich, unterstütze ich auch mir unbekannte Personen.

HG_10 Ich tue anderen Menschen oft ohne Vorbehalte oder Erwartungen etwas Gutes.

HG_13 In einer Notsituation würde ich wahrscheinlich spontan mein Leben riskieren, um fremde Menschen zu retten.

MC_1 Ich hinterfrage offen die Entscheidungen von Autoritäten oder Vorgesetzten.

MC_3 Es ist schon vorgekommen, dass ich Personen vor den Kopf gestoßen habe aufgrund meiner moralischen Überzeugungen.

MC_18 Wichtige Veränderungen für alle versuche ich auch gegen den erklärten Widerstand der Allgemeinheit durchzusetzen.

MC_20 Ich kämpfe gegen unrechte Anweisungen ,,von oben”, auch wenn es mich am Ende mehr kostet als dass es mir nützt.

MC_23 Im Konfliktfall konfrontiere ich die Täter.

CC_2 Unabhängig von meiner eigenen Position gehe ich entschieden gegen Gruppen von Menschen vor, die andersdenkenden Menschen drohen.

CC_4 Ich verteidige durch mein Handeln Demokratie und Meinungsfreiheit unter allen Umständen.

CC_5 Ich kämpfe für Menschenrechte, wenn ich diese bedroht sehe.

CC_6 Ich protestiere gegen Mehrheitsentscheidungen, wenn durch sie Freiheit und Gerechtigkeit eingeschränkt werden.

CC_7 In einer autoritären Diktatur würde ich mich trotz aller Gefahren dem Widerstand anschließen.

Note. $\mathrm{PP}=$ peer punishment; $\mathrm{HG}$ = help-giving; $\mathrm{MC}=$ moral courage; $\mathrm{CC}=$ civil courage. 